ORIGINAL ARTICLE

\title{
Social representations of physical education teachers concerning the game: a qualitative study in Chile
}

\author{
Alejandro Almonacid-Fierro ${ }^{1 \mathrm{ABCDE}}$, Jessica Mondaca Urrutia ${ }^{1 \mathrm{ABCD}}$, Sergio Sepúlveda-Vallejos ${ }^{2 \mathrm{ABCD}}$, \\ Karla Valdebenito ${ }^{2 \mathrm{ABCD}}$ \\ ${ }^{1}$ Faculty of Education, Universidad Católica del Maule, Chile \\ ${ }^{2}$ Doctorate in Education, Universidad Católica del Maule, Chile
}

Author contributions: A - Study design; B - Data collection; C - Qualitative analysis; D - Manuscript preparation; E Funds Collection

\begin{abstract}
Background

and Study Aim

The objective of this research was to determine the social representations of the game in physical education teachers belonging to the Chilean educational system, searching for the sense and meaning given by the educators to the game aspect.

Material and The study sample consisted of 14 physical education teachers, who were chosen by the convenience Methods sampling method. Semi-structured interviews were used to collect data from the participants, maintaining gender equity. The analysis of the data obtained was by means of content analysis and the NVivo 11 program was used to process the data.

Results Our research indicates that of the categories analyzed, the highest was the role of the game (22.29\%), demonstrating the relevance given by teachers to the game in the development of meaningful learning. On the contrary, the category characteristics of the game $(17.42 \%)$, describe how teachers visualize the contributions of play at the educational level, in this sense, the role of the game goes beyond motor contributions, but also provides tools for social and cognitive development.

Conclusions: For the teachers, the game promotes autonomous and proactive actions of the students, which will be beneficial to understand that playfulness in education implies not to put in contradiction the rational and emotional faculties. This comprehensive view is called full attitude, and it is a relevant step toward the understanding of the game from a complex perspective. In this area, it is evident that, in the social representations of the participating teachers, the game constitutes a natural environment in which children develop, where the physical education teacher should create an environment that facilitates the game, facilitating the expression of autonomy, freedom, creativity, and playfulness.

Keywords: game, playfulness, physical education classroom, learning.
\end{abstract}

\section{Introduction}

Children's play is an activity in which the child sets in motion the mechanisms of imagination, the way of seeing the world around them, transforming it, developing creativity and giving the possibility of opening up to others [1-4]. Whether at school or in the family environment, children devote part of their time to play, depending on their ages and preferences. In all cases, the game contributes to the development of the child's personality, which should be taken into account in primary education classrooms and by physical education teachers in particular [5-7]. The game involves enjoyment, not only for the children but also for those who guide the game. The effectiveness of play for learning is related to the positive emotions it generates since actions are mobilized by an intrinsic reward [8-10].

In this context, the game produces pleasure, is motivating, and generates positive emotions, since, if children did not have this internal drive, guided by an intrinsic reward, they would not invest time in this activity. Consequently, play is an activity that is done for the pleasure of doing it, it does not have a utilitarian goal, but, in the long run, it will be very useful for life in society

\section{(c) Alejandro Almonacid-Fierro, Jessica Mondaca Urrutia,}

Sergio Sepúlveda-Vallejos, Karla Valdebenito, 2021

doi:10.15561/26649837.2021.0606
[11-13]. The literature, reports that when investigating the needs of the child's personality and corporeality, the game is part of the essential activities of human nature, being characterized as a spontaneous, functional, and satisfactory action, a process that allows the child to enter an illusory and imaginative universe, stimulating greater self-control, since he/she will have to deal with conflicts derived from social rules, better controlling his/ her impulses through self-regulation [14-16]. However, few parents and teachers are aware of the importance of play for the healthy physical and psychological development of children. Sometimes it is limited to a pastime, disconnected from more important functions than the entertainment of the youngest; however, through play, children manage to control their distress to express their feelings and fantasies, permeating the real and the imaginary $[2,3,6]$.

Playful activity, consisting of play and fun, is a pedagogical tool for the performance and full development of students in the elementary classroom. In the present research, the game is an educational means that allows the development of physical, psychological, social, and spiritual potentialities, from within the person being educated, these constitute the support of all learning in the elementary classroom $[3,8]$. The game at school provides 
unique moments of fun, joy, relaxation, and a commitment to learning and responsibilities [17, 18]. For authors such as Aras [1] and Athey [2], play is a necessity in the life of human beings, throughout their lives and not only as entertainment, or moments of pleasure, but moments conducive to the development of creativity, socialization, reasoning, motor coordination, cognitive, affective and psychomotor domains. The game can be seen as a bridge that connects reality with the world of imagination, since, through the child's play, adults can understand how he or she sees and constructs their world, what problems they face, how they would like their life to be, and make their concerns known $[4,11,19,20]$. Children often express through their actions what they find difficult to put into words, in other words, play is their language that deserves respect, even if it is not fully understood.

From the theoretical, the study is based on the Social Representations Theory (SRT). This theory provides an understanding of the social thinking of teachers, whenever practices happen in school institutions are conditioned by beliefs, values, models, and symbols, which social psychology calls social representations [21-23]. The analysis of SRT allows reflecting on the pedagogical practice developed in schools, and specifically in the classroom, allowing teachers to ask themselves about their practices and the possible effects of their pedagogical work on their students' learning [24-26]. According to Abric [27], this knowledge is constituted by lived experiences and by the circulation of information about a social object among the elements of a given social group [28-30]. The analysis of social representations allows us to reflect on the beliefs and practices held by teachers regarding the constructed game in the physical education classroom.

Using the game in educational situations not only provides a real means of learning but also allows perceptive and competent adults to learn about children and their needs [17, 31-33]. In the school context, this translates to teachers being able to understand where children are in their learning and overall development, which in turn gives educators an indication of how to promote new learning, within the affective, cognitive, and motor domains $[2,8,11,34]$. According to the abovementioned, the teacher's role in playful development has to be based on trust, affection, encouragement, praise, limits, placed in a sincere, clear, and affectionate way, allowing interaction between the adult and the children. The teacher must be able to respect and nurture the child's interest, affords him/her possibilities to be involved in the process, or else the richness that play represents will be lost $[4,6,12,35,36]$. When playing, the teacher should create a bond with his or her student and allow a climate of safety to be established, he or she should set a goal for each activity and organize the time to be used.

In this context, the representations about the game by teachers will allow understanding of the sense and meaning given by physical education teachers, to the playful component that appears in the game, revealing how teachers conceive aspects such as leadership, obedience to rules, collaboration, competition, respect and tolerance in the physical education classroom [37-40]. This requires understanding that the game is a necessity, regardless of age, and should not be considered as entertainment, but as a learning process. Consequently, from the playful perspective, it is understood as the need of human beings to communicate, to feel, to express themselves, and to produce emotions oriented to entertainment, fun, recreation, which leads to a real generating source of emotions [41]. The game and playfulness contribute to good physical and mental health, facilitating the process of socialization, communication, and construction of knowledge, in addition to the full and integral development of the individuals involved in the teachinglearning process.

The objective of this research was to determine the social representations of the game in physical education teachers belonging to the Chilean educational system, searching for the sense and meaning given by the educators to the game aspect.

\section{Material and Methods}

\section{Participants.}

The participants of the study were physical education teachers from public primary schools in the province of Talca, Maule Region, Chile. Fourteen semi-structured interviews were conducted maintaining gender equity ( 7 women and $7 \mathrm{men}$ ). Participants who met the inclusion criteria of the study were involved. The inclusion criteria were: physical education teachers working in the city of Talca, Maule Region, Chile; at least three years of professional experience in the school system; public school teachers working in primary education. Exclusion criteria were defined as: teachers with fewer than three years of professional experience; general education teachers. Theoretical saturation was achieved when reaching saturation of the response alternatives.

\section{Research Design.}

This research is a qualitative study, based on the interpretive-comprehensive paradigm [42], which was performed in the region of Maule, Chile, between April and September 2020. Before data collection, the researchers obtained written informed consent to ensure the confidentiality of the names of the individuals, taking into account privacy and emphasizing voluntary participation. Participants were informed about the purposes of the research and their authorization was requested to record the interview, to safeguard ethical aspects. The interview was performed via Zoom or Skype, due to the sanitary emergency the country is going through, to maintain the sanitary conditions established by the authorities. In addition to using an audio recorder, manual observations were made to clarify the possible intentions of the teachers at the time of the interview, which had an average duration of 60 minutes, rigorously following the Helsinki protocol for research with human beings. The interview was selected as a methodological resource due to its flexible characteristics, understanding that the application of the technique allows an interactive 
process between the researcher and the interviewees [43]. The interview guideline contemplated questions such as the following: what is your work experience with respect to the game in the physical education classroom? What is the most recurrent behavior of children in the classroom when you propose play? How do children who present behavioral problems when they play share themselves in the classroom? What would be your greatest strengths for working with play in the physical education classroom? What would be the greatest strengths to work with the game in the physical education classroom? How do you approach the didactics of the game in the classroom from a pedagogical approach? Given your experience as a teacher, what recommendations would you make to the Initial Training (IT) to address the playful perspectives of the game?

\section{Qualitative Analysis}

To examine and interpret the data, content analysis was used, which constitutes a research methodology with systematic descriptions that allow an interpretation and understanding of meanings [44]. The content analysis made it possible to identify common recurring issues and to determine the main themes that summarize the opinions collected by the study participants. Content analysis was applied to analytically examine the transcribed material from the individual interviews and focus groups, dividing the text into relatively small content units and subjecting them to descriptive treatment, with the idea of converting the phenomenon into data that can be scientifically treated and building with them a body of knowledge about the social representations of teachers regarding the game in the physical education classroom. Following the guidelines of content analysis, the transcripts of the interviews and focus groups were read, and the recordings were listened to repeatedly to find the units of meaning, in terms of codes, inductively. It should be noted that the dimensions were specified as primary categories, and were obtained from the review of the theoretical framework [45]. Under these, dimensions were grouped as codes and then the categories were obtained from the systematic and repeated reading of the participants' reports. NVivo 11 software was used for data processing.

\section{Results}

The model is presented below, whose macro category focuses on the perception of the game construct by the physical education teachers. In the table, two previous categories emerge that evidence the representation of the game by the interviewed subjects, that is, didactics of the game and playful perspective of the game; each story presented has a code that expresses the interview (I), the number (no.) and the corresponding page (p.).

Previous category: Didactics of the game, primary category: Role of the game

The category "Role of the game" has $22.29 \%$ of the testimonies in the study, the highest of all, demonstrating the relevance given by the studied teachers to the role of the game in the development of meaningful learning in children. This category defines how a group of people with different academic backgrounds and professional experiences, focus on the fact that the game is a fundamental activity not only in education, but also in life.

"The game accompanies us at all ages from we are children until we are adults, where the playful part is lost a little in our daily life, something I do not agree with since the game would help us to regulate and better channel our actions. Making better decisions, facing failures in a better way, etc. In short, there are many strengths that the game provides, such as regulating your energies and learning from healthy competition." (E, no. 5, p. 1)

"I see the game as an activity, a process, that helps a lot in so many areas of a person, in the motor, physical, emotional, and cultural development, with the typical games of a country, games that have been played for many years and that help children culturally, they are a way of passing on traditions and customs, and that favors the inclusion of everyone in the classroom." (E, no. 1, p. 3)

After reviewing the testimonies, it is understood that the game is transversal and contributes to all the areas in which the subject develops. The game is the best way for children to unfold their potential and be able to understand them. According to the account of the teachers

Table 1. Systematization Model

\begin{tabular}{|c|c|c|c|c|}
\hline $\begin{array}{l}\text { Macro } \\
\text { Category }\end{array}$ & $\begin{array}{l}\text { Previous } \\
\text { Categories }\end{array}$ & Descriptor & $\begin{array}{l}\text { Primary } \\
\text { Categories }\end{array}$ & Frequency \\
\hline \multirow{6}{*}{ Game/Learning } & \multirow{3}{*}{ Game didactics } & \multirow{3}{*}{$\begin{array}{l}\text { Category that describes the strategies and } \\
\text { methodologies of the game used by the } \\
\text { teacher as a learning tool. }\end{array}$} & Game role & $22,29 \%$ \\
\hline & & & Teacher role & $6,62 \%$ \\
\hline & & & Learning & $16,37 \%$ \\
\hline & \multirow{3}{*}{$\begin{array}{l}\text { Playful } \\
\text { perspective of } \\
\text { the game. }\end{array}$} & \multirow{3}{*}{$\begin{array}{l}\text { Category that gathers the teacher's } \\
\text { perception of the proposal of the game in } \\
\text { the classroom and education in all its areas. }\end{array}$} & $\begin{array}{l}\text { Student's } \\
\text { actions }\end{array}$ & $16,37 \%$ \\
\hline & & & $\begin{array}{l}\text { Gaming } \\
\text { benefits }\end{array}$ & $6,62 \%$ \\
\hline & & & $\begin{array}{l}\text { Game } \\
\text { characteristics }\end{array}$ & $17,42 \%$ \\
\hline
\end{tabular}


studied, when children play, they expand their bodily capacity, their perception, their relationship with others, they discover the world and know the laws and rules.

"For me, the game should always be throughout everyone's life, and it depends on the stage the child is in. I think that right now the concept of the game has been lost very much and dangerously at even pre-basic ages." (E, no. 6, p. 2)

Making the game the object of intervention in physical education classes is a useful way to assume another rationality for this space-time, which associates the interests and needs of children. The game is a human activity, in which imagination, fantasy, and reality interact in the production of new possibilities of interpretation, expression, and action by children, as well as new possibilities of building social relationships with other subjects.

Previous category: Didactics of the game, primary category: Teaching role

The category "Teaching role" has $6.62 \%$ of the testimonies and is within the primary category related to the role that the teacher must accomplish at the moment of proposing the game within an educational context, and how this term is inserted within the initial training of physical education teachers.

"The importance of the game, the benefits it has... in fact, I would make early childhood motor skills mandatory in the major. At least in physical education. I think it is too important a subject that is not given the importance it should have. It would help us work on collaboration, empathy, respect, and self-esteem through the game." (E, no. 8, p. 5)

"There is a great lack of educating others about the importance of the game, and I say others, with colleagues, or the parents themselves, that when sometimes play is mentioned to them, they associate it with something basic, that does not have much relevance. I think that there is a lack of understanding of the game as a pedagogical resource, that there is no criticism from those who do not understand the concept of the game and its importance in the development of students". (E, no. 4, p.3)

According to the narratives, the teacher should be someone who gets involved with the students and, at the same time, gives importance to the game. The teacher must focus on the dynamism of the process and the integration of knowledge, observing and documenting individual and group processes. In the account, the role of Physical Education in the school context, its uniqueness, meaning, and social function can be observed.

"You are a teacher and the students are students, but you have to be part of the class, that is, you are a guide, a model practically for the children, and if you do not feel part of the class for a child, it is demotivating." (E, no. 3, p. 4)

Physical Education is about the relationship of a domain of knowledge that focuses on the dimension of doing; nevertheless, it includes the conceptual and attitudinal dimension that the teacher must establish as the central focus of teaching actions and, consequently, use the game as a pedagogical resource for the development of these dimensions.

Previous category: Didactics of the game, primary category: Learning

Within the primary category related to learning, it is crucial to mention how the game is present in the children's perception of this process is subjective, since they have different learning rhythms and methods. The physical education class is presented as a stage where they receive other stimuli that many times favor deconcentration. This category represents $16.32 \%$ of the analyzed reports.

"In individual game, it could be said that even the student does it a little out of competition with the classmate next to him. In the classroom, competitive play is very frequent, but not in the sense of competition. For example, when they do an exercise badly and the team wins, I give the point to the other team because they did not follow the instructions of the exercise, or they skipped such and such material or stepped outside the mat., etc." (E, no. 11, p. 5)

According to the narrative, part of the learning comes from how the game is applied and the variants that are incorporated into it. Learning is built from meaningful learning experiences that transcend and extend across more than one domain.

"Children are competitive, sometimes it is not bad to give the competitive part, as long as the recreational and value aspects are not left aside, but children themselves have that competitive part and in children, it is more evident, that is why we must insist on respecting the rules, to know how to win and how to lose." (E, no. 2, p. 2)

"The idea is to vary from the beginning, from individual work to teamwork, because children, especially when they are young, have a hard time working as a team, for example, in first grade, there are fights in all classes because they do not know how to share, they do not know how to work as a team, so the game helps us for teamwork and cooperation, including the gender issue." (E, no. 14, p. 6)

Learning does not take place exclusively in the formal school system, since children can contribute their cultural capital, their interests and their scholastic concerns at any time and in different contexts. What could be more interesting and stimulating than learning through play? It is possible to build a pedagogy of play in the school, effectively and efficiently connected to the school classroom.

Previous category: Playful perspective of the game, primary category: Student's actions

This term was selected within the playful perspective of the game and reaches $16.32 \%$ of the narratives. This category is very important since it develops how the teachers perceive that the student behaves when game 
instances are proposed. Teachers evidenced different realities, from frustration, to, in other cases, extreme happiness.

"They wait a lot for that moment when they can play and as a teacher, you know that, so you have to motivate this type of students, so that they become positive leaders in the game space, with full autonomy." (E, no. 10, p. 3)

"My students expect physical education class, and you have to respond to this expectation of the children, but always with the conviction that they will learn, therefore, one has to take advantage of this instance of more freedom in physical education, to teach them from the point of view of cooperation with the other partner through educational games." (E, no. 7, p.2)

According to the teachers' testimonies, children perceive the game as an instance of recreation and that, in those games where there is collaboration, social skills are generated which, although the children do not realize it, will be very useful to them in their development as integral persons with values. Taking into account that social skills are strategies that children learn and that allow them to behave appropriately in different environments and help them to initiate or manage social interaction in different environments and with a number of people, they should be taught in the early childhood environment, since it is in this period that children learn about behavior and social expectations with the game taking on a fundamental role.

"For my students, the physical education class is happiness, as if the children "explode" with happiness. They wait a lot for that moment, to be able to develop it. They know it is their moment because they will be able to play their games, they will be able to develop differently, it will be from the proposal that they will generate." (E, no. 13, p. 5)

The game is a means for children to adjust their behavior to behaviors that favor their coexistence and life in society. It takes up play as a common denominator at school age, being one of the most effective mediating activities to transform certain evolutionary achievements into habits and instrumental skills at the service of other, more complex ones.

Previous category: Playful perspective of the game, primary category: Benefits of the game

This category has $6.62 \%$ of the totality of the narratives in the study. This category concerns the teacher's perception of how the implementation of play in the physical education classroom benefits students, especially those with socioemotional problems.

"I use the game as a diagnosis, with the diagnosis I realize which child presents some signs of not wanting to share, or which child is shyer, which child is more skilful, sometimes in the same game." (E, no. 12, p. 3)

"From my experience at school, the game for children with social-emotional difficulties is very useful, because, through different didactic strategies, they feel involved, when you give them responsibilities in the game, as a leader, for example, they play a very important role, and that encourages them." (E, no. 7, p. 1)

According to the statements, the implementation of the game in the physical education classroom has many benefits for students, especially for those who have some level of socioemotional difficulties. The game provides the expression of positive emotions and the opportunity to canalize and control the negative ones, in what is called social and emotional learning.

"Some of my students have difficulties at home, those who are insecure, so through the game they can improve that part, self-improvement, selfesteem, confidence, solidarity, hygiene habits. Everything is incorporated from the transversal and attitudinal point of view." (E, no. 1, p. 3)

In this context, learning processes are framed in environments where emotions are key. A safe, affective environment, without fear, such as the one that favors the game, is the one that allows friendly relationships that expand our areas of understanding, thus fostering the pleasure of learning, which will propitiate the full development of the potential of each subject.

Previous category: Playful perspective of the game, primary category: Characteristics of the game

The category "Characteristics of the game" describes how the physical education teacher visualizes the contributions that the game delivers to the children at an educational level and how it can become a learning enhancer in other subjects, transforming education into an integral collaborative work for the benefit of the student. The stories represent $17.42 \%$ and point out:

"You observe them, and you realize how many games they come up with, they relate it to their motor expression, they act, they chase each other on horseback, that is, at that moment, which is not a game guided by an adult or teacher, I feel that it is the period of greater freedom for children, to develop their imagination, their creativity. And if they have rules, they are the ones who incorporate them or create them. So, the game is learning, it is not only a means to, but it is rather an objective, the objective that they play." (E, no. 5, p. 2)

"The game is a moment of entertainment that generates a moment of well-being for the children, a participatory moment where they collaborate with their classmates, they have fun, there is a social aspect that is also affected and the children like to play, so it is a good resource to stimulate the class and get through the class until the end." (E, no.12, p. 4)

According to the teachers' statements, the integration of games not only brings motor benefits to the physical education classroom, but also provides the child with tools for social and cognitive development. Therefore, it is important to articulate physical education, and the game 
in particular, in other subjects and learning areas; in this sense, areas such as language and mathematics should be articulated and connected with diverse motor expressions. In the account of the subjects investigated, it is observed that the role of the game in Physical Education is of utmost importance, since it strengthens collaborative and social aspects, favoring the integral development of the child. Furthermore, it is presented in the school context as an enhancer of learning for other subsectors; nevertheless, this relationship of the game learning is still not valued in the educational environment, being that the game is used by the teacher as a means to achieve an atmosphere of entertainment and motivation within the class.

\section{Discussion}

Using the game in educational situations not only provides a real means of learning, but also allows adults to learn about children and their needs. In the school context, this means that teachers can understand where children are in their learning and overall development, which allows educators an indication of how to promote new learning within the affective, cognitive and motor domains $[5,31$, 32]. In this context, the physical education teacher should provide free and directed play situations, satisfying the learning needs of children. The teacher could be called an initiator and mediator of learning, as play becomes a pedagogical tool for the deployment of content in the classroom $[8,17]$. In this line, the social representations that emerge from the key informants' discourse respond to this idea, since it is a perspective that is, at the same time, reconstituted by school physical education teachers $[4,46,47]$. This represents how each physical education teacher approaches the game in his or her pedagogical practice, since the game in primary schools is manifested differently; in other words, as a pedagogical resource or as a recreational activity, depending on the pedagogical intentionality of the teacher $[12,35]$.

The findings reported by the present study reveal that the physical education teacher can use different techniques to apply the contents and, even so, introduce the games for a better development of the classes and achieve its objective [40, 48, 49]. The physical education teacher can use different techniques to apply the contents and, as such, introduce the games for a better development of the classes and achieve its objective [40, 48, 49]. If the games are properly presented, the educational process will be satisfactory for all involved, since the playfulness influences the educator's teaching factors and also favors the students' learning [7]. Therefore, the game and playfulness are techniques that can be used to achieve the success of the subject's education, since the child will feel as a constructor subject of his training and will take learning to the context beyond the school space $[1,33$, 50]. The teachers interviewed emphasize the importance of cooperation through play, which favors healthy competition, to work on autonomy, self-knowledge, selfcriticism and self-esteem, inclusion, respect for rules, knowing how to win, knowing how to lose, and the gender question.
In terms of the previous category "Didactics of the Game", this is constituted from the primary categories role of the game, teaching role and learning, which coincident with the literature in the role that the game plays in the physical education classroom through the studies of Balan and Shaao [5], Hortigüela Alcalá and Hernando Garijo [7], Barba-Martín, Bores-García [33] and Gil-Arias, Harvey [51]. These studies show that teachers value play in terms of learning and socialization. On the other hand, the perception that one of their contributions is learning with pleasure does not ensure that they know how to proceed in practice, to value the game in its origin, respecting its characteristics, which is to be a free, unpredictable, symbolic, regulated and well-defined action in terms of space and time of realization.

The category "Playful Perspective of the Game" is composed of the categories student's actions, benefits of the game and characteristics of the game, in which the teachers give an account of how the playful aspect is approached in the physical education classroom. In this context, it is presented how educators resolve the contradiction that arises when they propose to use games to teach certain curricular contents, given that one of their characteristics is the priority on the process of playing, and not on its effects or results. This is one of how the game and the playful perspective have been brought to the school, since it is considered promising for making learning and teaching meaningful $[8,11,34,51]$. In the interviewees' accounts, it is observed that the game is one of the most important ways in which children obtain essential knowledge and competencies. Consequently, they value environments that favor play, exploration and hands-on learning. This is because development and learning are complex and holistic; however, all areas of development, including motor, cognitive, social and emotional competencies, can be encouraged through play, as shown in studies by Athey [2], Hoffmann and Russ [6], Hortigüela Alcalá and Hernando Garijo [7], Colliver and Veraksa [17], Abad Robles, Collado-Mateo [31] and Pesce, Masci [52], In fact, in playful experiences, children use at the same time a whole range of competences, an issue that occurs frequently in the physical education classroom.

In this sense, teachers report that play activities, when well-planned, foster children's development and learning competencies more effectively than any other school activity. Along these lines, the literature reports that, through play, children learn to forge bonds with others, and to share, negotiate and resolve conflicts, in addition to contributing to their capacity for self-affirmation. The game also teaches children leadership skills, in addition to relating in groups, coping with social challenges and overcoming their fears $[12,19,53]$. In short, the student's actions are favored to the extent that the teacher proposes the game as a learning resource and as a socialization tool.

\section{Conclusions}

The game, as an activity that promotes autonomous interaction, is a process that generates complexity and 
has the potential to develop students' autonomy and proactivity. Therefore, the game can be valued as an instance of autonomy and proactivity development, as it proposes actions with sense and meaning. At the same time, the game has the potential to promote values such as listening, conversation and collaboration, since it is a tool and rather an excuse for conversation. Understanding the place of playfulness in education also implies not putting in contradiction the rational versus the emotional faculties, since in the playful spirit of a child everything is present and connected, things are not yet separated, as they will later be separated in the intellectual, the emotional, the volitional, science, art, religion, etc. This integrality is called the full attitude of children in the game, and it is a relevant step toward the understanding of the game from a complex perspective.

According to the social representations of the teachers interviewed, the game is the natural environment in which children develop and develop. The study reports that the physical education teacher should create an environment that facilitates play, that is, a moment in which autonomy, freedom, creativity and playfulness are expressed. This is because, in order for children to play with greater involvement, the central function of the teacher is to become part of this system, which implies bringing out the playful spirit that children carry within them. The above, in the perspective that the game, with its spaces and objects, is the activity of childhood that allows the process of progressive adaptation to the world to occur, since in exploration and free play the impulse to know arises spontaneously. On the contrary, accelerating development, skipping stages, focusing primarily on the achievement and acquisition of "cognitive" learning, has an inhibiting effect on this natural impulse to know and learn.
In this context, the necessity emerges for studies that guide teacher training programs based on the knowledge of their representations, conceptions, preconceptions and pedagogical ideas. The valorization of the game by teachers, based on the learning and socialization, and the perception that learning with pleasure, does not ensure that they know, effectively, how to proceed, to valorize the game in its origin, respecting the primary characteristics of the game, which is to be a free, unproductive, unpredictable, symbolic, regulated and well-defined action in terms of space and time of realization. Consequently, discourse and practice may be distance, giving rise to the question "is the game really in the classroom?" It is possible that, in the case of our research, the similarity of the answers, especially regarding the importance for learning, is the result of individual and group reflection on their professional experience in the physical education classroom.

\section{Limitations of the study}

This study has a number of limitations. The research was conducted only with practicing teachers; for future studies, teachers in initial training could be considered. On the other hand, after the Covid-19 pandemic, it would be interesting to observe the teachers' classes, in order to triangulate the discourse with classroom practice.

\section{Acknowledgment}

Thanks to the physical education teachers who participated in the research. No financial support was involved in the research.

\section{Conflict of interest}

The authors declare that there are no conflicts of interest.

\section{References}

1. Aras S. Free play in early childhood education: a phenomenological study. Early Child Development and Care, 2016;186(7):1173-84. https://doi.org/10.1080/03004430.2015.1083558

2. Athey I. Contributions of Play to Development. In: Yawkey TD, Pellegrini AD, editors. Children's Play. 1st ed., Routledge; 2018. P. 8-28. https://doi.org/10.4324/9781315099071-2

3. Bateson P, Martin P. Play, Playfulness, Creativity and Innovation. Cambridge: Cambridge University Press; 2013. https://doi.org/10.1017/CBO9781139057691

4. Kafai YB, Burke Q. Constructionist Gaming: Understanding the Benefits of Making Games for Learning. Educational Psychologist, 2015;50(4):313-34. https://doi.org/10.1080/00461520.2015.1124022

5. Balan V, Shaao M. Study on Improving the Specific Content of Teaching Physical Education Classes through Movement Games in Primary School. Procedia - Social and Behavioral Sciences, 2014;117:173-8. https://doi.org/10.1016/j.sbspro.2014.02.197

6. Hoffmann JD, Russ SW. Fostering pretend play skills and creativity in elementary school girls: A group play intervention. Psychology of Aesthetics,

\section{Creativity, and the Arts, 2016;10(1):114-25.} https://doi.org/10.1037/aca0000039

7. Hortigüela Alcalá D, Hernando Garijo A. Teaching Games for Understanding: A Comprehensive Approach to Promote Student's Motivation in Physical Education. J Hum Kinet. 2017;59:17-27. https://doi.org/10.1515/hukin-2017-0144

8. de Freitas S. Are Games Effective Learning Tools? A Review of Educational Games. Journal of Educational Technology \& Society, 2018;21(2):74-84.

9. Jiang J, Vauras M, Volet S, Wang Y. Teachers' emotions and emotion regulation strategies: Self- and students' perceptions. Teaching and Teacher Education, 2016;54:22-31. https://doi.org/10.1016/j.tate.2015.11.008

10.Tyng CM, Amin HU, Saad MNM, Malik AS. The Influences of Emotion on Learning and Memory. Frontiers in Psychology, 2017;8(1454). https://doi.org/10.3389/fpsyg.2017.01454

11.Cohen D. The Development of Play. 4th ed. 4th Edition. New York: Routledge, 2019. Revised Edition of the Author's The Development of Play, 2006.: Routledge; 2018. https://doi.org/10.4324/9781315121703

12.Miller A. Games Centered Approaches in Teaching Children \& Adolescents: Systematic Review 
of Associated Student Outcomes. Journal of Teaching in Physical Education, 2015;34(1):36-58. https://doi.org/10.1123/jtpe.2013-0155

13.Romero M, Usart M, Ott M. Can Serious Games Contribute to Developing and Sustaining 21st Century Skills? Games and Culture, 2015;10(2):148-77. https://doi.org/10.1177/1555412014548919

14.Alexander PA, Greene JA. Selfregulation in education: Routledge; 2017. https://doi.org/10.4324/9781315537450

15.Chen L-X, Sun C-T. Self-regulation influence on game play flow state. Computers in Human Behavior, 2016;54:341-50. https://doi.org/10.1016/j.chb.2015.08.020

16.DiBenedetto MK. Self-regulation in Secondary Classrooms: Theoretical and Research Applications to Learning and Performance. In: DiBenedetto MK, editor. Connecting Self-regulated Learning and Performance with Instruction Across High School Content Areas, Cham: Springer International Publishing; 2018, p. 3-23. https://doi.org/10.1007/978-3-319-90928-8_1

17.Colliver Y, Veraksa N. The aim of the game: A pedagogical tool to support young children's learning through play. Learning, Culture and Social Interaction, 2019;21:296-310. https://doi.org/10.1016/j.lcsi.2019.03.001

18. Yasemin A, John J. Teachers' Experience and Reflections on Game-Based Learning in the Primary Classroom: Views from England and Italy. International Journal of Game-Based Learning (IJGBL), 2015;5(1):1-17. https://doi.org/10.4018/ijgbl.2015010101

19.Marsh K. Creating bridges: music, play and well-being in the lives of refugee and immigrant children and young people. Music Education Research, 2017;19(1):60-73. https://doi.org/10.1080/14613808.2016.1189525

20.Uzun de Freitas MLdL. A evolução do jogo simbólico na criança [The evolution of symbolic play in children]. Ciências \& Cognição. 2010;15:145-63. (In Portuguese).

21.Abou-Gebran R, Trevizan Z. Social representations in the construction of professional identity and teachers' activity. Acta Sci Educ, 2018;40:34534. https://doi.org/10.4025/actascieduc.v40i2.34534

22.Chaib M, Loureiro L. Social representations, subjectivity and learning. Cadernos de Pesquisa. 2015;45:358-72. https://doi.org/10.1590/198053143201

23.Martikainen J. Social representations of teachership based on students' and teachers' drawings of a typical teacher. Social Psychology of Education, 2019;22(3):579-606. https://doi.org/10.1007/s11218-019-09490-w

24.Lahlou S. Social representations and social construction: the evolutionary perspective of installation theory. In: Sammut G, Andreouli E, Gaskell G, Valsiner J, editors. The Cambridge Handbook of Social Representations, Cambridge: Cambridge University Press; 2015. P. 193-209. https://doi.org/10.1017/CBO9781107323650.017

25.Lo Monaco G, Piermattéo A, Rateau P, Tavani JL. Methods for Studying the Structure of Social Representations: A Critical Review and Agenda for Future Research. Journal for the Theory of Social Behaviour, 2017;47(3):306-31. https://doi.org/10.1111/jtsb.12124

26. Sinha C, Mishra AK. The Social Representations of Academic Achievement and Failure. Psychological Studies, 2015;60(2):160-9. https://doi.org/10.1007/s12646-014-0285-3

27.Abric J-C. A structural approach to social representations. Representations of the social: Bridging theoretical traditions. Malden: Blackwell Publishing; 2001.

28.Marková I. The making of the theory of social representations.
Cadernos de Pesquisa, 2017;47(163):358-75. https://doi.org/10.1590/198053143760

29. Tolstykh N, Ter-Avanesova N, Chernyak N. Social Representations About School and Learning in Different Groups of Participants of the Educational Process. Psychological Science and Education, 2019;24(6):5-15. https://doi.org/10.17759/pse.2019240601

30. Wachelke J. Social Representations: A Review of Theory and Research from the Structural Approach. Universitas Psychologica, 2012;11:729-41. https://doi.org/10.11144/Javeriana.upsy11-3.srrt

31.Abad Robles MT, Collado-Mateo D, Fernández-Espínola C, Castillo Viera E, Giménez Fuentes-Guerra FJ. Effects of Teaching Games on Decision Making and Skill Execution: A Systematic Review and Meta-Analysis. International Journal of Environmental Research and Public Health, 2020;17:505. https://doi.org/10.3390/ijerph17020505

32.Allsop Y, Jessel J. Teachers' Experience and Reflections on Game-Based Learning in the Primary Classroom: Views from England and Italy. International Journal of Game-Based Learning, 2015;5:1-17. https://doi.org/10.4018/ijgbl.2015010101

33. Barba-Martín RA, Bores-García D, Hortigüela-Alcalá D, González-Calvo G. The Application of the Teaching Games for Understanding in Physical Education. Systematic Review of the Last Six Years. International Journal of Environmental Research and Public Health, 2020;17(9): 3330. https://doi.org/10.3390/ijerph17093330

34.Chatzipanteli A, Digelidis N, Karatzoglidis C, Dean R. A tactical-game approach and enhancement of metacognitive behaviour in elementary school students. Physical Education and Sport Pedagogy, 2016;21(2):169-84. https://doi.org/10.1080/17408989.2014.931366

35.Kirk D. Teaching Games in Physical Education: Towards a pedagogical model. Revista Portuguesa de Ciências do Desporto, 2017;2017:17-26. https://doi.org/10.5628/rpcd.17.S1A.17

36. Yilmaz M, Karakaya YE, Savucu Y. The state of preparedness of prospective physical education and sports teachers. Pedagogy of Physical Culture and Sports, 2020;24(6):323-30. https://doi.org/10.15561/26649837.2020.0608

37.Lodewyk KR. Relations Between Epistemic Beliefs and Instructional Approaches to Teaching Games in Prospective Physical Educators. Physical Educator 2015;72(4):677-700. https://doi.org/10.18666/TPE-2015-V72-I4-6479

38.Mandigo J, Lodewyk K, Tredway J. Examining the Impact of a Teaching Games for Understanding Approach on the Development of Physical Literacy Using the Passport for Life Assessment Tool. Journal of Teaching in Physical Education, 2019;38(2):136-45. https://doi.org/10.1123/jtpe.2018-0028

39.Moy B, Renshaw I, Davids K. Variations in acculturation and Australian physical education teacher education students' receptiveness to an alternative pedagogical approach to games teaching. Physical Education and Sport Pedagogy, 2014;19(4):349-69. https://doi.org/10.1080/17408989.2013.780591

40.Varea V. Exploring play in school recess and physical education classes. European Physical Education Review, 2018;24(2):194-208. https://doi.org/10.1177/1356336X16679932

41.Hassinger-Das B, Toub TS, Zosh JM, Michnick J, Golinkoff R, Hirsh-Pasek K. More than just fun: a place for games in playful learning. Journal for the Study of Education and Development, 2017;40(2):191-218. https://doi.org/10.1080/02103702.2017.1292684 
42.Given L. The SAGE Encyclopedia of Qualitative Research Methods. 2455 Teller Road, Thousand Oaks California 91320 United States: SAGE Publications, Inc.; 2008. https://doi.org/10.4135/9781412963909

43.Kvale S, Brinkmann S. Interviews: Learning the craft of qualitative research interviewing. Sage; 2009.

44.Graneheim UH, Lindgren B-M, Lundman B. Methodological challenges in qualitative content analysis: A discussion paper. Nurse Education Today, 2017;56:29-34. https://doi.org/10.1016/j.nedt.2017.06.002

45.Miles MB, Huberman AM, Saldana J. Qualitative data analysis. A methods sourcebook; 2014.

46.Harvey S, Light RL. Questioning for learning in game-based approaches to teaching and coaching. Asia-Pacific Journal of Health, Sport and Physical Education, 2015;6(2):175-90. https://doi.org/10.1080/18377122.2015.1051268

47.Kim I, Ward P, Sinelnikov O, Ko B, Iserbyt P, Li $\mathrm{W}$, et al. The Influence of Content Knowledge on Pedagogical Content Knowledge: An EvidenceBased Practice for Physical Education. Journal of Teaching in Physical Education, 2018;37:133-43. https://doi.org/10.1123/jtpe.2017-0168

48.Ucus S. Elementary School Teachers' Views on Gamebased Learning as a Teaching Method. Procedia Social and Behavioral Sciences, 2015;186:401-9. https://doi.org/10.1016/j.sbspro.2015.04.216
49.Yuksel HS. Experiences of Prospective Physical Education Teachers on Active Gaming within the Context of School-Based Physical Activity. European Journal of Educational Research, 2019;8(1):199-211. https://doi.org/10.12973/eu-jer.8.1.199

50.Chiva-Bartoll Ó, Salvador-García C, Ruiz-Montero PJ. Teaching games for understanding and cooperative learning: can their hybridization increase the motivational climate of physical education students? Croatian Journal of Education, 2018;20:561-84. https://doi.org/10.15516/cje.v20i2.2827

51.Gil-Arias A, Harvey S, García-Herreros F, González-Víllora S, Práxedes A, Moreno A. Effect of a hybrid teaching games for understanding/sport education unit on elementary students' self-determined motivation in physical education. European Physical Education Review, 2021;27(2):366-83. https://doi.org/10.1177/1356336x20950174

52.Pesce C, Masci I, Marchetti R, Vazou S, Sääkslahti A, Tomporowski PD. Deliberate Play and Preparation Jointly Benefit Motor and Cognitive Development: Mediated and Moderated Effects. Frontiers in Psychology, 2016;7(349). https://doi.org/10.3389/fpsyg.2016.00349

53.Hesterman S, Targowska A, Saratsis M, Kaiko J. Everyone benefits when children play. Australia: Early Childhood Australia; 2020.

\section{Information about the authors:}

Alejandro Almonacid-Fierro; Corresponding author); https://orcid.org/0000-0002-8328-017X; aalmonacid@ucm.cl; Faculty of Education, Universidad Católica del Maule; Talca, Chile.

Jessica Mondaca Urrutia; https://orcid.org/0000-0002-4903-1882; jmondaca@ucm.cl; Faculty of Education, Universidad Católica del Maule; Talca, Chile.

Sergio Sepúlveda-Vallejos; https://orcid.org/0000-0001-5986-5373; ssepulveda@ucm.cl;Doctorate in Education, Universidad Católica del Maule; Talca, Chile.

Karla Valdebenito; https://orcid.org/0000-0002-7896-6628; kvaldebenitog@gmail.com; Doctorate in Education, Universidad Católica del Maule; Talca, Chile.

Cite this article as:

Almonacid-Fierro A, Mondaca Urrutia J, Sepúlveda-Vallejos S, Valdebenito K. Social representations of physical education teachers concerning the game: a qualitative study in Chile. Pedagogy of Physical Culture and Sports, 2021;25(6):373-381. https://doi.org/10.15561/26649837.2021.0606

This is an Open Access article distributed under the terms of the Creative Commons Attribution License, which permits unrestricted use, distribution, and reproduction in any medium, provided the original work is properly cited (http://creativecommons.org/licenses/by/4.0/deed.en).

Received: 05.10.2021

Accepted: 19.11.2021; Published: 30.12.2021 